\title{
A História da Hemoterapia no INCA
}

\section{History of Hemotherapy at INCA}

\author{
Maria da Conceição Muniz Guadagnino', José Guido de
}

Azevedo $^{2}$ e Darcy da Silva Guimarães ${ }^{3}$

D esde a criação do Centro de Cancerologia, instituído pelo Decreto Lei do Presidente da República no 378, de 13 de janeiro de 1937, até a mudança para as dependências do H ospital Gaffrée e Guinle, em 1946, do já Instituto de Câncer, órgão subordinado ao Serviço Nacional de Câncer, criado pelo D ecreto Lei do Presidente da República $\mathrm{n}^{\circ}$ $3.643 / 41$, as transfusões de sangue eram efetuadas como prática heróica e extrema.

O s próprios médicos as executavam em seus pacientes, utilizando o método de "braçoa-braço" com as famosas seringas de Jubet e, a maioria das vezes, os doadores eram captados entre os próprios funcionários do hospital.

Com a evolução dos métodos e procedimentos usados em hemoterapia, principalmente com a fabricação industrial de frascos com anticoagulantes, que permitiam a conservação do sangue em geladeira, o primeiro serviço de transfusão de sangue no Instituto de Câncer foi fundado pelo médico M ário Kröeff em 1946, em uma das dependências do H ospital Gaffrée e Guinle, em sala anexa ao Laboratório de Anatomia Patológica.

N essa ocasião, já com o Banco de Sangue instalado, foi designado chefe o médico $\mathrm{Gil}$ M oreira Filho, sendo ele, portanto, o transfusionista pioneiro do Instituto $\mathrm{N}$ acional de C âncer. Com isto, as primeiras provas cruzadas em lâminas já sendo executadas, os trabaIhos passaram a ser procedidos em moldes mais modernos, inclusive com a introdução rotineira da determinação do Fator $\mathrm{Rh}$.

Vários nomes de cirurgiões, clínicos e técnicos passaram pelo então Banco de Sangue, tais como os médicos $H$ élio $D$ uarte
N ogueira de Sá, Amaury Barbosa da Silva, Lena Bulcão Vianna, Roberto Góes, O nofre Silva, Moisés Averbuck, Wilson Altoé e Francisco Arinelli $\mathrm{H}$ erédia; e os funcionários pioneiros G ertrudes de Assis, M arilda M eale, Cildo Correia da Silva, Sebastião de M oraes, este oriundo do setor de Patologia Clínica, Sebastião Coelho, H elena Dias C ardoso, Ivone Silva, Afonso Benito Franzesi, M aria Ondina da Costa Rodrigues, D yla Pereira de Almeida, Leda de O liveira Barbosa, D enise Bastos Linhares, Plínio M orais Lucena e a copeira Nadyr.

Com a oficialização do Instituto $\mathrm{N}$ acional de Câncer, pelo Decreto ํㅜ 50.251, de 28 de janeiro de 1961, o Banco de Sangue passou a constar do Regimento Interno do IN CA, no Artigo $n=61$, com todas suas atribuições e sob a chefia do médico Gil M oreira Filho.

Em O utubro de 1970, o IN CA, nesta ocasião sob a subordinação da FEFIEG (Federação das Escolas Isoladas do Estado da Guanabara), instalou no Serviço de Hemoterapia, a U nidade de Separação Celular Emil J. Freireich, sendo o primeiro serviço do Brasil a executar aferese em equipamento de fluxo contínuo - Celtrifuge AM IN CO USA.

$N$ essa mesma década, foi instalado o laboratório de Imuno-Sorologia, pioneiro, em todo o Brasil, na implantação de testes para D oença de $C$ hagas, Sífilis e H epatite B.

O Serviço, dado o seu prestígio no M inistério da Saúde, teve representação na Comissão $\mathrm{N}$ acional de $\mathrm{H}$ emoterapia e na Câmara Técnica de Hemoterapia do M inistério da Saúde, na pessoa do Chefe do Serviço, o médico José Guido de Azevedo.

${ }^{1}$ M édico - Chefe do Serviço deH emoterapia do IN CA $\quad{ }^{2}$ M édico - Ex-Chefe do Serviço deH emoterapia do IN CA ${ }^{3}$ A ssessor do D iretor G eral do IN CA 
$\mathrm{N}$ a década de oitenta, foram contratados mais médicos, biólogos e técnicos de laboratório e se deu o desenvolvimento da era do Fracionamento de Sangue para a obtenção de hemocomponentes. $\mathrm{N}$ a mesma época, a unidade de Separação Celular foi ampliada para dar apoio ao recém-inaugurado Centro Nacional de Transplante de M edula Ó ssea CEM O, com aquisição das separadoras de Células $\mathrm{H}$ aemonetics 30 Plus e Dideco BVT 796. Em 1984, o Setor de ImunoSorologia adquiriu, por influência da Comissão $\mathrm{N}$ acional de $\mathrm{H}$ emoterapia, equipamentos de radioimunoensaio para 0 diagnóstico de vírus da hepatite $B$, tendo participado da elucidação de um surto dessa B pelo uso de gamaglobulina, no Brasil.

$N$ essa mesma década, foi designado o SubSistema de H emoterapia da cidade do Rio de Janeiro, com o Serviço de H emoterapia do INCA orientando a instalação das unidades hemoterápicas do H ospital Fernandes Figueira e do Hospital Raphael de Paula e Souza.

Através da Portaria ${ }^{\circ} 20$, de 15 de janeiro de 1980, do M inistério da Saúde, o Serviço de $\mathrm{H}$ emoterapia do Instituto $\mathrm{N}$ acional de Câncer passou a exercer a análise prévia de produtos derivados do sangue humano, prevista na Lei 6.360, de 23 de setembro de 1976. Em julho de 1985, ele foi o primeiro no Brasil na realização de teste para Aids em doadores de sangue e em hemoderivados.

$\mathrm{N}$ a década de noventa, o Serviço alcançou um grande desenvolvimento tecnológico nas áreas de Imuno-H ematologia, Imuno-
Sorologia, Fracionamento de sangue e Afere se, tendo sido beneficiado com a construção de moderníssimas instalações, numa área aproximada de $1.000 \mathrm{~m}^{2}$. E inicia o primeiro século de um novo milênio abrigando o Banco de Sangue de Cordão U mbilical e Placentário, para a oferta pública de células precursoras de medula óssea.

D esde 0 início até a presente data, 0 Serviço de Hemoterapia do IN CA teve oS seguintes médicos como chefes: Gil M oreira Filho (I950/1963), José Guido de Azevedo (1963/1994) e M aria da Conceição M uniz Guadagnino (a partir de 1994).

Porém a H istória do Serviço de Hemoterapia no INCA é, mais do que a história de um Serviço, a história do próprio Instituto Nacional de $C$ âncer. E dos Diretores que 0 conduziram e o conduz: M ário Kröeff (1938/ 1941), Alberto Lima de M oraes Coutinho (1941/1954), Luiz Carlos de O liveira Júnior ( 1954/1956), Antônio Pinto V ieira (1956/1962), M oacyr Alves dos Santos Silva (1962/1963 e 1972/1974), Francisco Fialho (I963/1967 e 1969/1970), J orge Sampaio de M arsillac M otta (1967/1969), Ugo de Castro Pinheiro Guimarães (1970/1972), Adayr Eiras de Araújo (1974/1978), João Carlos C abral (1978), Wolfgang George Lamprecht (1978/1979), H iram Silveira Lucas (1979/1980), Ary Frauzino Pereira (I980/1985), Geraldo M atos de Sá (1985/1986), Walter Roriz de Carvalho (I986/1990), M arcos Fernando de Oliveira M oraes (1990/1998) e J acob Kligerman (a partir de 1998). 